Original Research Paper

\title{
3D Cinematography in the Cinema Art of Kazakhstan: Technological, Film Studying and Social Aspects
}

\author{
Vladimir Ilyich Popov \\ Kazakh National Academy of Arts Named after T. Zhurgenov, Almaty, Republic of Kazakhstan
}

Article history

Received: 08-10-2015

Revised: 09-11-2015

Accepted: 10-11-2015

Email: popovfilm@mail.ru

\begin{abstract}
The article discusses the problems of formation and study of the new direction in the audiovisual culture and art-3D cinema. The film set of the first Kazakhstan 3D film, i.e., complicated for production feature 3D film named "Returning to the "A" directed by Yegor MikhalkovKonchalovskiy was the experimentation facility of the research. The purpose of the study is to conduct a comprehensive evaluation of the integral characteristic of the communicative potential-social and psychological climate in the shooting team of first Kazakh 3D movie. A comprehensive analysis of the social and psychological climate in the shooting team staff of 3D movie has revealed its positive evaluation in all the communicative tests as the best, friendly, good, close to the maximum group cohesion index, sufficient level of sociability and democratic style of leadership. The author's definition to the communications as a social and informative metabolism is given. The model of film production is developed by types of communications. 3D film-making technology can extend the capabilities of the communication potential of film art as a means of mass communication.
\end{abstract}

Keywords: 3D Cinema, Audiovisual Arts, Film Director, Social Studies, Communications

\section{Introduction}

Stereoscopic cinema or 3D cinematography. Screen art is inherently linked to the evolution of the technical and technological achievements, as there is mutual interdependence and creative design and technology component of the film industry (Hayes, 1998). Modern 3D-technology makes the screen image more convincing and expressive, lead to the creation of a screen culture of the new virtual world (Low, 2001). 3D remains one of the most powerful technologies of film medium in modern cinematography (Ukai and Howarth, 2008).

Three-dimensional image born by a new era was marked by a real revolution in the world of cinema (Zone, 2007; Mendiburu, 2009). The phenomenal success of the 2009 James Cameron's 3D movie Avatar has become the main catalyst for the rapid development of 3D cinema worldwide (Avatar, 2009; Duncan and Fitzpatrick, 2010).

The premiere of the full-length staged first Kazakh 3D movie "Returning to the ' $\mathrm{A}$ "' directed by Yegor Mikhalkov-Konchalovsky in 2011 marked the opening of the era of Kazakh 3D cinema. The film plot is based on real events during the war in Afghanistan, about the heroism and true friendship of two fellow soldiersRussian and Kazakh (Sugirbaeva, 2011; Khrabryi, 2009). The film slogan: "Story of Love and Friendship through Fire and Years". Scriptwriters-Vladimir Moiseenko, Alexander Novototsky-Vlasov.

Director of Photography of the film is Anton Antonov. Producer and the leading man starring legendary Major Kara-Arman Asenov. The shooting team also included a directing group (including directors: Anatoly Avshalumov, Meira Karbozov), administrative group, an acting group (the film involved both Kazakh and Russian actors-Seydulla Moldahanov, Berwick Aitzhanov, Denis Nikiforov, Gosha Kutsenko, Natalia Arinbasarova, Asha Matai, etc.), camera crew, sound crew, a group of film artists, a group of pyrotechnics, drivers, doctors etc.

Production: Kazakhfilm Film Studio named after Sh. Aymanov, together with production center Baiterek and PS TVC studio. The material was converted in 3D by $3 \mathrm{D}$ Azimut.

The purpose of the study is to conduct a comprehensive evaluation of the integral characteristic 
of the communicative potential-social and psychological climate in the shooting team of full-length feature 3D movie by creating a full-length staged first Kazakh 3D movie "Returning to the 'A"' directed by Yegor Mikhalkov-Konchalovsky.

\section{Related Data}

\section{Communications and Their Types}

The XXI century is called the century of new modern, computer, communication, 3D technologies and the rise of multicultural relations. This century requires from people a new way of thinking, qualitatively different education, higher communicative potential, a new type of behavior and interaction with people. The word "communication" itself comes from the Latin 'communico'do common, communicate. The communication, which plays a key role in human society (Shubrt, 2013), means converse, exchange of ideas, knowledge, emotions, behavior patterns, etc. (Pocheptsov, 2006).

There are the following types of communication:

- Intrapersonal-a conversation with himself, person's inner monologue, etc

- Interpersonal-it involves two communicants

- Group-within the group, between groups, an individual-a group

- Mass-a large number of people receive or use a message (cinema, television, radio, etc.) (Kashkin, 2007)

\section{Communications in the Film Production}

All four types of communications are typical of the film production:

- Intrapersonal-individual inner work of a scriptwriter, director on the script, an actor on the role, etc

- Interpersonal-relationships, exchange of information, interaction between the scriptwriter and director, director and actor, actor with the actor, etc

- Group-the relationship, exchange of information, cooperation between members of the shooting team

- Mass (audiovisual information) is transmitted to the masses (a mass communication)

Communications in the shooting team are classified into two groups:

- Internal-the relationship between the members of the group are major in film-making process

- External-through the film product-with the audience

We have developed the model of film production by types of communications (Fig.1).

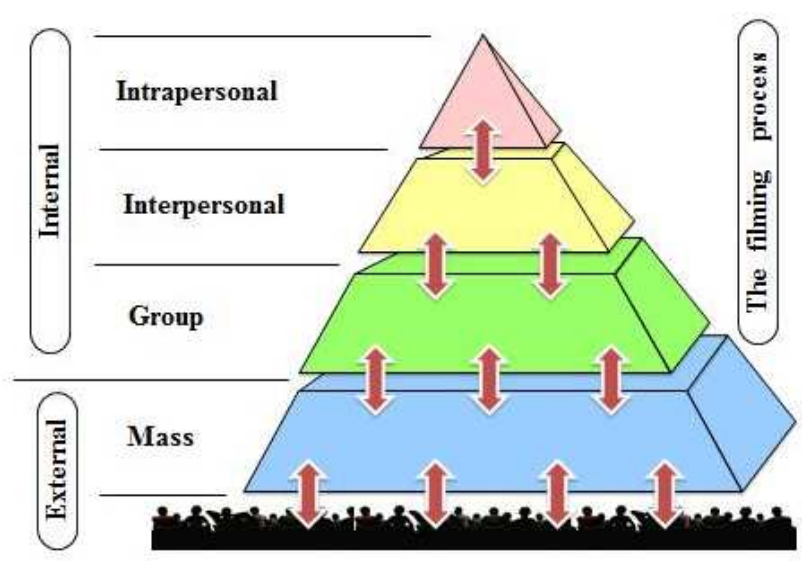

Fig. 1. The model of film production by types of communications

Communications are social communication and exchange of information and by analogy to the exchange of substance and energy, which is called metabolism, we can say that communication is social and information metabolism.

3D film-making technologies enable to extend the capabilities of the communication potential of film art as mass-communication tool.

\section{Social and Psychological Climate}

"Staff is a key to everything"-a phrase known in the Soviet period has the doubled relevance for film production-for both shooting team staff and for the frames of the film shot.

The director's art involves a creative organization of all film-making elements to create a single, harmonically coherent piece of art. This goal is reached by the director only if a creative team is established in a favorable atmosphere-a favorable social and psychological climate (Yershov, 2010).

This requires knowledge of the theoretical and practical bases of formation of communication, a favorable social and psychological climate, as well as tools-methods of its evaluation and monitoring. It is not accidentally that the classic manual on directing by P.M. Yershov is called: "Directing as Practical Psychology".

Social and Psychological Climate (SPC) of the staff is almost an integral feature of the condition of the team, it is socially conditioned; relatively stable system of attitudes of its members to the team as a whole. Social and psychological climate is always based on interpersonal relationships, so it is an indication of their condition (Afanasieva, 2003).

\section{Social and Psychological Climate}

The role of the leader in the creation of optimum SPC is crucial (Kalinina, 2004; Kuzmin et al., 2005). The leader can significantly impact the nature of interpersonal relationships in the staff, on attitude to joint activities, 
satisfaction with the work conditions and results, i.e., social and psychological climate, which largely depends on the efficiency of the organization as a whole.

Democratic style of develops sociability and trust of relationship, friendliness. At the same time, there is no feeling of solutions forced from outside, "from above". Participation of the team members in management, typical of this style of leadership, helps to optimize SPC.

The authoritarian style usually generates hostility, humility and flattery, envy and distrust. But if this style leads successful, which justifies its use in the eyes of a team; it contributes to the favorable SPC, such as in sports or army.

Laissez-faire style results in low productivity and poor quality of work, dissatisfaction with the joint activity and leads to the formation of unfavorable SPC. Laissez-faire style may be acceptable only in some creative teams (Kabachenko, 2006; Kudryashov, 1999; Tikhonov, 2006).

\section{Materials and Methods}

Methods of study: To accomplish the purpose of the study modern methodological basis was used-the main elements of a systematic approach to the use of information and analytical, bibliographical, historical, sociological, statistical scientific research methods. Sociological method of study was conducted through questionnaires and video interviews of shooting team members of staged full-length feature 3D movie "Returning to the 'A"" directed by Yegor MikhalkovKonchalovsky. We have carried out the sociological study of communication processes in the most important period of film-making-shooting. The sociological study used a representative sample-the entire key staff of the shooting team (50 people). We have evaluated the integral characteristic of human relationships (communications)-the social and psychological climate in the staff of the shooting team of full-length staged first Kazakh 3D movie directed by Yegor MikhalkovKonchalovsky "Returning to the 'A"'.

To evaluate the communicative potential and to study the social and psychological climate in the staff of the shooting team we have developed a comprehensive assessment methodology using the existing social and psychological tests and new methodological approaches, video interviewing, enabling to carry out its assessment and monitoring, we have developed a questionnaire to carry out a sociological study.

The questionnaire was drawn up in accordance with the recommendations for the development of questionnaires for sociological research (Devyatko, 2009) and included the introduction, personal data part, 30 questions. Nine of the 30 questions of the questionnaire used modern informative social and psychological tests and techniques for the study of the integrated characteristics of the communications-social and psychological climate in the team, carefully selected after a study of the existing methods of investigation of this problem in the literature (Myers, 1997; Anastasi and Urbina, 2001; Volkov et al., 2006; Ilyin, 2004; Karelin, 2005a).

\section{Results}

The results of the social and psychological tests and techniques used in the questionnaire in the course of sociological study revealed the following.

Express methods for the study of social and psychological climate in the organization by O.S. Mikhalyuk and A.Yu. Shalyto (Karelin, 2005b) to enable to reveal the emotional, behavioural and cognitive components of relations in the unit. The methods were developed at the Department of Social Psychology, Faculty of Psychology of St. Petersburg University. The psychological climate of the primary organizational unit is understood by the authors as a socially conditioned, relatively stable system of relations between the members of the unit to the unit and the organization as a whole. Analysis of the data obtained using this method is standardized and has a calculation algorithm, based on which the various aspects of attitude to the staff for each person individually is analyzed. Thus, the following options of social and psychological climate in the organization are possible: (1) very favorable; (2) generally favorable; (3) totally unsatisfactory; (4) generally unsatisfactory; (5) trends are contradictory and vague. According to these methods, the social and psychological climate in the Shooting Team Staff (STS) is defined as very favorable.

The psychological climate on the emotional level reflects relations prevailing in the staff, the nature of business cooperation and attitude to the significant events of life. The psychological climate is formed through the "psychological atmosphere"-also the emotional state of the group, which, however, takes place in relatively short periods of time and which in turn creates situational emotional states of the staff. Defining psychological climate of the group according to schematic map by L.N. Lutoshkin (Karelin, 2005c) allowing revealing whether it is favorable or unfavorable confirmed that the psychological climate in the STS is also favorable.

Defining the psychological climate in the organization by 7 characteristics. This technique is based on a specific type of survey involving all members of a certain department. Each of them is given a questionnaire containing a table with the 7 most important characteristics of behavior and attitude that must be present in an ideal staff, which the respondents evaluate on a 5-point scale. The test shows the level of the seven most important characteristics of the staff and, consequently, the social and psychological climate in it. These 
characteristics are as follows: Responsibility; community spirit; cohesion; sociability; openness; organization; awareness. The data obtained are added to the defined average score (for each indicator) and entered on a graph that illustrates the social and psychological climate chosen to study the staff. Defining psychological climate in the organization by 7 characteristics on a 5-point scale has revealed that for the shooting team staff the average score by 7 characteristics is 4.2, which is interpreted as an optimal psychological climate.

Evaluation of the psychological atmosphere in the organization. The technique is used to evaluate the psychological atmosphere in the organization. It is based on the method of semantic differential. Response for each of the 10 scale points is measured from left to right from 1 to 9 points. The more left-handed is " $X$ ", the lower the score, the more favorable psychological climate in the organization is, according to the responder. Total indicator ranges from 10 (the most positive score) to 90 (most negative) points. On the basis of the individual profiles, an average profile is created that characterizes the psychological atmosphere in the organization. The technique is interesting because it allows anonymous testing, which increases reliability. The psychological atmosphere in the organization was evaluated by 10 characteristics in points (from 10-the most positive evaluation, to 90 points-the most negative evaluation). The lower the total score, the better the atmosphere in the organization. Evaluation of the psychological atmosphere in the shooting team is 26 points, which characterizes it as a positive, favorable.

Group cohesion is a very important parameter, indicating the degree of group integration, its cohesion into a unified whole. Definition of the group cohesion index by Seashore in points (from a minimum of 5 to a maximum of 19 points) showed that the group cohesion index in the shooting team is 15 points-close to the maximum positive score.
Sociability evaluation test by V.F. Ryakhovsky (Karelin, 2005d), according to which the defined respondents' sociability may have 7 levels-from the lowest possible to the highest level, revealed that $95 \%$ of STS members have sufficient level of sociability.

According to results of the method of psychological study of the respondent's social environment by sociometric evaluation of the actual and the desired place in the respondent's group, $80 \%$ of respondents indicated correspondence of the real and the desired place in the shooting team staff, $20 \%$ of respondents-a desire to take a more central (more high-status) position in the team. Thus, the overwhelming majority of the staff members indicated the correspondence of actual and desired place in the shooting team staff.

Methods of determining the leadership style by V.P. Zakharov and A.L. Zhuravlev (Karelin, 2005e) (authoritarian, liberal or democratic) have revealed that the management style in the STS is democratic.

In summary, the results of the sociological study are given in Table 1.

Thus, conducted comprehensive analysis of the social and psychological climate in the shooting team staff of full-length feature 3D movie "Returning to the 'A" directed by Yegor Mikhalkov-Konchalovsky has revealed its positive evaluation in all tests as the best, friendly, good, close to the maximum group cohesion index (according to Seashore), sufficient level of sociability and democratic style of leadership.

At the same time, $100 \%$ of the respondents to the question "Who is generally responsible in your entire shooting tem for the social and psychological climate?" responded that the head of the shooting team-the director.

Thus, the analysis of the SPC in the shooting team staff of full-length feature 3D movie "Returning to the 'A'" directed by Yegor Mikhalkov-Konchalovsky has revealed its positive evaluation in all the communicative tests, which could not but affected the film itself.

Table 1. Results of the social and psychological tests and techniques of sociological study in the shooting team staff

\begin{tabular}{|c|c|}
\hline Test or method & Results of study in the shooting team staff \\
\hline $\begin{array}{l}\text { Express methods for the study of social and psychological } \\
\text { climate in the organization by O.S. Mikhalyuk and A.Yu. Shalyto }\end{array}$ & $\begin{array}{l}\text { The social and psychological climate in } \\
\text { the shooting team staff is defined as very favorable }\end{array}$ \\
\hline Defining the psychological climate in the organization by & Average score for 7 characteristics is \\
\hline 7 characteristics (author's modification of the test) & 4.2 (optimal psychological climate) \\
\hline $\begin{array}{l}\text { Defining psychological climate of the group } \\
\text { according to schematic map by L.N. Lutoshkin }\end{array}$ & $\begin{array}{l}\text { The psychological climate in the shooting } \\
\text { team staff is favorable (good) }\end{array}$ \\
\hline Definition of the group cohesion index by Seashore & $\begin{array}{l}\text { The group cohesion index in the shooting team staff is } \\
\text { close to the most positive evaluation ( } 15 \text { points) }\end{array}$ \\
\hline $\begin{array}{l}\text { Evaluation of the psychological } \\
\text { atmosphere in the organization }\end{array}$ & $\begin{array}{l}\text { The psychological atmosphere in the organization is } \\
26 \text { points (positive, favorable psychological atmosphere) }\end{array}$ \\
\hline $\begin{array}{l}\text { Methods of determining the leadership } \\
\text { style by V.P. Zakharov and A.L. Zhuravlev }\end{array}$ & The leadership style is democratic \\
\hline Sociability evaluation test by V.F. Ryakhovsky & $95 \%$ of the team members have sufficient level of sociability \\
\hline $\begin{array}{l}\text { Method of psychological study of the } \\
\text { respondent's social environment }\end{array}$ & $\begin{array}{l}80 \% \text { of respondents indicated correspondence of the real } \\
\text { and the desired place in the shooting team staff }\end{array}$ \\
\hline
\end{tabular}


Thus, Kazakh first 3D movie was nominated from Kazakhstan for Oscar Award in the category "Best Foreign Language Film," was the opening film at the II International Action Film Festival in Astana (2011), at the VII International Film Festival "Eurasia" in Almaty (2011), 33rd Moscow International Film Festival (2011), Tashkent International Cinema Forum "Golden Guepard" (2011), at Cinema Mundi, Brno (2012) (Returning to the 'A', 2011a; 2011b; 2011c; Official page of Returning to the 'A', 2011; 63 Countries Vie, 2011). The film received praise and recognition of the audience and film critics.

\section{Discussion}

According to the study results, to create high-quality film product it is necessary to form a favorable, optimal social and psychological climate in the shooting team.

To improve film-making personnel management and film production quality, improve the film-making process and SPC in the shooting team it is recommended to include in the staff the communication expert, to use the cutting-edge film-making technology and financial incentive (wage increase).

The results of this study can be used for in-depth study and understanding of the leader's role and the formation of the communicative potential both in creative and any other staff.

The developed approaches to SPC evaluation in the shooting team of staff can be used as a methodological tool for assessing and monitoring the social and psychological climate and communications in practice of both the directors, creative staff and leaders of teams and organizations at different levels.

Communications are social relations and exchange of information and by analogy to the substance and energy exchange, which is called metabolism, communication is social and information metabolism.

Under the results of the research conducted it was advised to include a communication specialist into the staff, to use advanced technologies of film production and financial incentives in order to improve the film production personnel management and films quality, to develop the filming and social climate in the film crew. This use of the advanced technologies of the film production allowed creating the first Kazakhstan film released in $3 \mathrm{D}$ format.

3D film-making technology can extend the capabilities of the communication potential of film art as a mass-communication tool.

\section{Conclusion}

For the first time the leading role of the main person at the film set, i.e., the director, in the creative team and filming, has been proved using advanced scientific methods of the research. His/her leading role in the forming of favorable positive social climate, being a quintessence of the communicative potential of both the creative team and later the film made by this crew, was proved.

We demonstrated importance to use the advanced achievements of science and technologies allowing to open the potential of the screen arts in a new way during film creation, using virtual world and virtual space made with the help of $3 \mathrm{D}$, to extend the fourth type of the communications-mass media or mass communication with new content and possibility to bring creative concept of the director with great strength of artistic expression, reality and accuracy, to give rise to empathy, suspense and participation in the $3 \mathrm{D}$ cinema world created by the director. The film set of the first Kazakhstan highly-artistic 3D film, i.e., complicated for production feature 3D film named "Returning to the 'A"' directed by Yegor Mikhalkov-Konchalovskiy was the experimentation facility of the research. We made the cinema study analysis of the first 3D film in Kazakhstan devoted to the theme of heroism and courage, act of bravery and patriotism, which set the high standard for any future 3D films and cinema productions in general. The author's definition to the communications as a social and informative metabolism is given.

3D technologies of the cinema production allow extending potential possibilities of cinema art communication as a communication media and offering big challenges to the further scientific researches and findings in this field in the future.

\section{Acknowledgement}

We thank Yegor Mikhalkov-Konchalovsky, director of Kazakhstan's first 3D film "Returning to the 'A", Arystanbek Muhamediuly, Minister of Culture and Sport of the Republic of Kazakhstan, Bibigul Nussipzhanova, rector of Kazakh National Academy of Arts named after T.Zhurgenov, Baubek Nogerbek, PhD doctors of art, Marina Goldovskiy, academician, Professor, doctor of Arts for their support and assistance in scientific work.

\section{Funding Information}

This work was supported and funded by the Ministry of Education and Science of the Republic of Kazakhstan and Kazakh National Academy of Arts named after T.K. Zhurgenov.

\section{Author Contribution}

Vladimir Popov developed the plan of the research and carried out the study, data collection of the study sample, analysis and writing of the manuscript.

\section{Ethics}

This article is original and contains unpublished material. The author has no conflicts of interest in the development and publication of the current research. 


\section{References}

63 Countries Vie, 2011. Foreign language film Oscar. 63 Countries Vie.

Afanasieva, T.A., 2003. Social and psychological climate. ISI Msudt, Moscow.

Anastasi, A. and S. Urbina, 2001. Psychological Testing. 1st Edn., St Petersburg, Peter.

Avatar, https://en.wikipedia.org/wiki/Avatar_(2009_film)

Devyatko, I.F., 2009. Methods of Sociological Study. 1st Edn., Moscow, SAM.

Duncan, J. and L. Fitzpatrick, 2010. The Making of Avatar. 1st Edn., Harry N. Abrams, New York, ISBN-10: 0810997061, pp: 272.

Hayes, R.M., 1998. 3-D Movies: A History and Filmography of Stereoscopic Cinema. 1st Edn., McFarland, Jefferson, NC, ISBN-10: 0786405783, pp: 414.

Ilyin, Y.P., 2004. Psychology of individual differences. St Petersburg, Peter.

Kabachenko, T.S., 2006. Psychology of management. Russian Pedagogical Agency, Moscow.

Kalinina, A.O., 2004. Factors influencing formation of the psychological climate. VLADOS, Moscow.

Karelin, A.A., 2005a. Psychological tests. VLADOS, Moscow.

Karelin, A.A., 2005b. Psychological tests. VLADOS, Moscow.

Karelin, A.A., 2005c. Psychological tests. VLADOS, Moscow.

Karelin, A.A., 2005d. Psychological tests. VLADOS, Moscow.

Karelin, A.A., 2005e. Psychological tests. VLADOS, Moscow.

Kashkin, V.B., 2007. Basics of communication theory. AST, Vostok-Zapad, Moscow.

Khrabryi, O., 2009. Afghan breakdown. Express K, Almaty.

Kudryashov, L.D., 1999. Who to be a leade: Psychology of management. EKMOS.

Kuzmin, E.G., I.P. Volkov and E.N. Yemelyanov, 2005. Leader and staff. Severozapad, St Petersburg.
Low, C., 2001. "CyberWorld" in IMAX 3-D. Take One Film Television Canada, 33: 36-37.

Mendiburu, B., 2009. 3-D Movie making: Stereoscopic movie making. Focal Press, Oxford.

Myers, D., 1997. Social psychology. Progress, Moscow.

Official page of Returning to the 'A', 2011. http://bayterekfilm.kz/films/vozvrashhenie-v-a/

Pocheptsov, G.G., 2006. Communication theory. ReflBook, Vakler, Moscow.

Returning to 'A'. $2011 \mathrm{a}$. http://www.kinopoisk.ru/film/491882

Returning to the 'A'. $2011 \mathrm{~b}$. https://en.wikipedia.org/wiki/Returning_to_the_\%27 $\mathrm{A} \% 27$

Returning to the 'A'. 2011c. https://ru.wikipedia.org/wiki/Возвращение_в_«A»

Shubrt, J., 2013. Niklas Luhmann: Problem of communication within functionally differentiated society. Sociological Studies, 1: 5-15.

Sugirbaeva, M., 2011. Hero lived next to us. Karavan. Almaty.

Tikhonov, M.Y., 2006. Features of management of creative teams: Soviet period of sociology development and modernity.

Ukai, K. and P.A. Howarth, 2008. Visual fatigue caused by viewing stereoscopic motion images: Background, theories and observations. Displays, 29: 106-116. DOI: 10.1016/j.displa.2007.09.004

Volkov, B.S., Volkova N.V., Gubanov A.V., 2006. Methodology and Methods of Psychological Study. 1 st Edn., Academic Project, Moscow.

Yershov, P.M., 2010. Directing as a practical psychology. Interaction of people in life and on stage. Directing as a construct/Rezhissura Kak Prakticheskaya Psikhologiya. Vzaimodeystvie Lyudey v Zhizni i Na Stsene. Rezhissura Kak Postro. 1st Edn., Mir iskusstva, ISBN-10: 5904407041.

Zone, R., 2007. The last great innovation: The stereoscopic cinema. SMPTE Motion Imaging J., 116: 518-523. DOI: 10.5594/J16034 